\title{
A SAÚDE DO TRABALHADOR NA ESTRATÉGIA DE SAÚDE DA FAMÍLIA: PERCEPÇÕES DA EQUIPE DE ENFERMAGEM
}

\author{
Maria de Lourdes Custódio Duarte ${ }^{1}$ Joice Carvalho Avelhaneda², Rodrigo Ritter Parcianello ${ }^{3}$
}

\begin{abstract}
RESUMO: O estudo objetivou analisar a percepção da equipe de enfermagem sobre a saúde do trabalhador de Estratégia Saúde da Família do sul do Brasil. Foram entrevistados todos os profissionais da equipe de enfermagem, totalizando seis trabalhadores. Os dados foram analisados seguindo os passos da análise temática e emergiram duas categorias: Questões que afetam a saúde da equipe de enfermagem e Sugestões da equipe de enfermagem para melhoria da saúde do trabalhador. Na primeira categoria foram evidenciados sobrecarga de trabalho, estrutura física, questão financeira, segurança, e sofrimento mental e físico. Os elementos que compõem a segunda categoria são a criação de um local para descanso e de grupos terapêuticos, além da necessidade de reconhecimento do trabalho. Conclui-se que a saúde dos trabalhadores deve ser pauta de reuniões com os gestores, visando melhorias das condições laborais que repercutem na saúde do trabalhador e, consequentemente, na qualidade da assistência prestada à população.
\end{abstract}

DESCRITORES: Enfermagem do trabalho; Saúde do trabalhador; Prevenção primária; Programa Saúde da Família.

\section{WORKER'S HEALTH IN THE FAMILY HEALTH STRATEGY: THE NURSING TEAM'S PERCEPTIONS}

\begin{abstract}
The study aimed to analyze the nursing team's perceptions on the health of the Family Health Strategy worker in the South of Brazil. All the professionals from the nursing team were interviewed, totalling six workers. The data was analyzed following the steps of thematic analysis, and two categories emerged: Issues which affect the nursing team's health and Suggestions from the nursing team for improving the worker's health. The first category evidenced overloading with work, the physical structure, financial issues, security, and mental and physical suffering. The elements composing the second category are the creation of a place for relaxation and the setting-up of therapeutic groups, as well as the need for recognition of the work. It is concluded that workers' health must be grounded in meetings with managers, with a view to improving work conditions which influence the workers' health and, consequently, the quality of the care given to the population.

DESCRIPTORS: Work nursing; Worker's health; Primary prevention; Family Health Program.

\section{LA SALUD DEL TRABAJADOR EN LA ESTRATEGIA DE SALUD DE LA FAMILIA: PERCEPCIONES DEL EQUIPO DE ENFERMERÍA}

RESUMEN: Este estudio tuvo la finalidad de analizar la percepción del equipo de enfermería acerca de la salud del trabajador de Estrategia Salud de la Familia del Sur de Brasil. Fueron entrevistados todos los profesionales del equipo de enfermería, totalizando seis trabajadores. Los datos fueron analizados considerando los pasos del análisis temático y resultaron dos categorías: Cuestiones que interfieren en la salud del equipo de enfermería y Sugerencias del equipo de enfermería para mejoría de la salud del trabajador. En la primera categoría, fueron evidenciados sobrecarga de trabajo, estructura física, cuestión financiera, seguridad, y sufrimiento mental y físico. Los elementos que componen la segunda categoría son la creación de un sitio para descanso y de grupos terapéuticos, además de la necesidad de reconocimiento del trabajo. Se concluye que la salud de los trabajadores debe ser pauta de reuniones con los administradores, a fin de buscar mejorías de las condiciones laborales que repercuten en la salud del trabajador y, consecuentemente, en la cualidad de la asistencia prestada a la población. DESCRIPTORES: Enfermería del trabajo; Salud del trabajador; Prevención primaria; Programa Salud de la Familia.

${ }^{1}$ Enfermeira. Mestre em Enfermagem Psiquiátrica e Ciências Humanas. Doutoranda pelo Programa de Pós-Graduação em Enfermagem da Universidade Federal do Rio Grande do Sul - UFRGS. Professora da Universidade Federal do Pampa.

${ }^{2}$ Enfermeira. Especialista em Gestão do Trabalho.

${ }^{3}$ Acadêmico de Medicina da Universidade Luterana do Brasil.

Autor correspondente:

Recebido: $13 / 08 / 2012$

Maria de Lourdes Custódio Duarte

Aprovado: 18/03/2013

Universidade Federal do Rio Grande do Sul

Rua Gonçalves Ledo, 20 - 90610-250 - Porto Alegre-RS-Brasil

E-mail:malulcd@yahoo.com.br 


\section{INTRODUÇÃO}

As preocupações com a saúde do trabalhador começaram a surgir com relevância na época da Revolução Industrial. Em grau crescente, os trabalhadores tornaram-se vítimas de doenças e acidentes ocupacionais, como o estresse, lesão por esforço repetitivo (LER), transtornos mentais, dentre outros. Baixos salários, jornadas extensas de trabalho e condições precárias para o desenvolvimento de suas atividades influenciam na saúde do trabalhador ${ }^{(1)}$.

Ressalta-se, contudo, que, em relação a essa época, a legislação trabalhista brasileira voltada para melhorias das condições de trabalho e diminuição de acidentes no contexto laboral tem evoluído bastante ${ }^{(2)}$. Nesse sentido, a Política Nacional de Saúde do Trabalhador, que entrou em vigor em 2004, visa à redução dos acidentes e doenças relacionadas ao trabalho, mediante a execução de ações de promoção, reabilitação e vigilância na área de saúde. Essa política objetiva garantir que o trabalho seja executado em condições que contribuam para a melhoria da qualidade de vida e para a realização pessoal e social dos trabalhadores, e sem prejuízo para a sua saúde ${ }^{(3)}$.

No contexto de trabalho da Enfermagem, os profissionais de enfermagem têm enfrentado condições insalubres, baixos salários, dupla ou tripla jornada de trabalho, sobrecarga física e emocional, acidentes de trabalho, que podem ocasionar danos à sua saúde. $\mathrm{O}$ estresse cotidiano está presente durante sua jornada de trabalho através do enfrentamento da dor, sofrimento de familiares e morte de pacientes ${ }^{(1,4)}$. Muitas vezes, o trabalhador cuida do usuário e deixa de cuidar da sua própria saúde, esquecendo-se de $\mathrm{si}^{(5)}$. Na enfermagem, por exemplo, as cargas físicas e psíquicas sofridas por esses trabalhadores apresentam-se em diferentes cenários, como hospital, serviços de saúde, ambulatórios, laboratórios, ou mesmo na Estratégia da Saúde da Família (ESF).

A motivação em realizar este estudo advém da observação do elevado número de profissionais de enfermagem em uma unidade da ESF que entraram em licença de saúde em decorrência do seu trabalho. Entende-se que essas questões trazem prejuízos não somente à saúde do trabalhador, mas também à saúde da população, que acaba sofrendo com o elevado absenteísmo e com a alta rotatividade dos profissionais, prejudicando a assistência à comunidade.

Acredita-se ser de extrema importância ter conhecimento sobre a saúde do trabalhador de enfermagem na ESF, a fim de proporcionar um ambiente laboral mais saudável, qualificando o trabalho por ele prestado à população. Assim, tem-se como questão norteadora: Qual a percepção dos trabalhadores de enfermagem sobre a saúde do trabalhador na ESF? Portanto, enfatiza-se a relevância deste estudo, tendo em vista a falta de estudos específicos sobre a saúde do trabalhador de enfermagem na ESF. Este estudo pretende contribuir para a formulação de estratégias de prevenção dos agravos à saúde que acometem esses profissionais, bem como contribuir para melhoria dos serviços prestados.

Dessa forma, tem-se por objetivo geral analisar a percepção da equipe de enfermagem sobre a saúde do trabalhador em Estratégia da Saúde da Família do Sul do país. E por objetivos específicos: identificar as principais questões que afetam a saúde da equipe de enfermagem da ESF e conhecer as sugestões da equipe de enfermagem sobre possibilidades de melhoria das condições de trabalho que repercutem em sua saúde.

\section{MÉTODO}

Este estudo tem caráter exploratório-descritivo, com abordagem qualitativa ${ }^{(6)}$, e foi realizado em uma unidade da ESF da região metropolitana de Porto Alegre-Rio Grande do Sul. Os participantes compreenderam a equipe em enfermagem da ESF: dois enfermeiros, dois técnicos de enfermagem e dois auxiliares de enfermagem, totalizando seis entrevistados. A composição dos participantes do estudo foi intencional, por convite, tendo como critério de inclusão o tempo mínimo de um ano de vínculo na ESF; e como critérios de exclusão, os profissionais que estivessem de férias ou licença saúde no momento da coleta de dados.

A coleta dos dados ocorreu em novembro de 2011 por intermédio de entrevistas semiestruturadas, após a aprovação do estudo pelo Comitê de Ética da Universidade Federal do Pampa, conforme Protocolo de número 063/11, sendo considerados os aspectos éticos envolvendo seres humanos, em conformidade com o previsto na Resolução 196/96 do Conselho Nacional de Saúde ${ }^{(7)}$. Os participantes assinaram o Termo de Consentimento Livre e Esclarecido após terem sido informados sobre os objetivos da pesquisa.

As entrevistas foram pré-agendadas conforme disponibilidade dos entrevistados e realizadas de forma individual e privativa, em uma sala reservada na referida unidade da ESF, com tempo de duração em torno de 30 minutos. As entrevistas foram gravadas com autorização prévia dos participantes do estudo e 
norteadas pelos questionamentos: Como você percebe a saúde do trabalhador de enfermagem nesta ESF? Você identifica alguma questão que afeta a saúde da equipe de enfermagem da ESF? Qual? Você teria alguma sugestão que melhorasse a saúde do trabalhador? Qual?

As frases verbalizadas pelos participantes do estudo foram transcritas e numeradas de um a seis, na ordem cronológica da realização das entrevistas, e denominadas de "E” para os enfermeiros, "T" para técnicos e "A" para auxiliares. Foi realizada a leitura integral das entrevistas, adotando-se o referencial de análise temática para apreciação crítica do conteúdo, buscando encontrar os trechos significativos para a constituição dos temas abordados nas obras pesquisadas, em relação ao objetivo do estudo. Seguindo-se os passos de pré-análise e exploração do material, foi possível a organização e leitura repetida do corpus de pesquisa $^{(6)}$.

Posteriormente, procedeu-se ao tratamento e interpretação dos resultados obtidos, que permitiram o agrupamento de ideias relevantes em categorias ${ }^{(6)}$, representadas por dois eixos temáticos de discussão. $\mathrm{O}$ referencial adotado para análise versa sobre a saúde do trabalhador.

\section{RESULTADOS}

\section{Questões queafetam asaúde da equipe de enfermagem}

Nesta categoria se encontram as principais questões que afetam a saúde do trabalhador de enfermagem da equipe da ESF estudada. São enfatizados vários fatores que desencadeiam doenças e/ou acidentes relacionados ao trabalho, afetando a saúde dos profissionais. Esses fatores são decorrentes de um processo de trabalho desorganizado e muitas vezes desestruturado. Assim, nesta categoria foram trazidos pelos entrevistados os seguintes assuntos: 1) sobrecarga de trabalho; 2) estrutura física; 3) questão financeira; 4) segurança; e 5) sofrimento mental e físico.

Os participantes do estudo enfatizaram a sobrecarga de trabalho devido ao elevado absenteísmo no cotidiano e à falta de contratação de profissionais, fazendo com que a demanda de trabalho fique distribuída entre os profissionais que compareceram ao trabalho:

Temos muitas atribuições e poucos profissionais. Tu tens que se sobrecarregar para preencher as lacunas locais que ficam abertas, no caso dos outros profissionais que não vêm, ah! (A4)
Muito atendimento, pouco profissional, falta de profissional. Sobrecarga em uns, e outros não. (T6)

A estrutura física foi outro aspecto salientado pelos participantes como uma questão que afeta a saúde da equipe de enfermagem. Eles apontaram que a unidade está em más condições de estrutura e que precisa ser reformada e ampliada, demonstrando as precárias condições de trabalho que esses profissionais enfrentam:

A gente precisava de mais salas de consultórios, precisava de uma salinha quando tivesse uma mãe que precisasse amamentar. (T3)

Temos falta de água aqui e não temos caixa d'água. Quando falta água, fechamos o curativo e as vacinas. Chegamos a pegar a água de balde na casa de uma colega para colocar na descarga no banheiro. (A2)

Já aconteceu de não ter uma maca adequada, um lençol para pôr numa cama, não ter um travesseiro para acomodar um paciente. (A4)

Outro aspecto relatado pelos profissionais da equipe de enfermagem como sendo uma questão que afeta a sua saúde foi o aspecto salarial, muitas vezes desmotivando o trabalhador, como expresso:

\section{O salário é um horror de baixo! (T3)}

A falta de segurança no ambiente de trabalho foi mencionada pelos entrevistados, pois muitos se sentiam inseguros ao trabalhar na ESF, devido à sua exposição no desempenho das atividades. Roubos e agressões físicas e verbais ocorrem no cotidiano da ESF, mesmo com a presença de guardas municipais, influenciando negativamente na saúde do trabalhador. Alguns recortes dos depoimentos:

O compressor necessário para o atendimento odontológico já levaram duas ou três vezes. Já teve também colega atacado. Paciente que vem alcoolizado ou alterado por outras drogas, chega na unidade e ameaça. (E1)

Eles agridem, continuam xingando e acham que a gente tem que resolver todos os problemas. Isso acontece diariamente. (T6)

Já fazia horas que o paciente gritava, ameaçando, que iria me matar, ai o guarda veio e retirou a faca que ele tinha. Foi levado para a delegacia, isto está em 
processo judicial agora. (A2)

A visita domiciliar (VD) é uma das atividades realizadas pela equipe de enfermagem, é considerada um dispositivo de cuidado aos usuários dos serviços de saúde de extrema exposição para os profissionais, principalmente pelo fato de a unidade da ESF estar situada em uma comunidade acometida pelo tráfico de drogas. A insegurança é expressa neste depoimento:

Tem a questão da segurança. A gente tem que ir lá nas casas, onde a gente fica exposto. São lugares que têm tráfico de drogas ou que é uma familia violenta. Tem que ter uma abordagem muito sutil, para que a pessoa não se sinta ofendida. (E5)

O diagnóstico de depressão e os sintomas de ansiedade foram relacionados pelos profissionais entrevistados com o trabalho desenvolvido na ESF. Alguns profissionais contam sua própria história para ilustrar sua trajetória entre psicólogos e psiquiatras. Outros, confessam que cuidam da saúde da população, mas que, no entanto, esquecem-se de cuidar da sua própria:

No final a gente só cuida dos outros e a nossa saúde é meio esquecida. Já tive problema de depressão por causa do trabalho. (A4)

Faz um ano que eu consulto com psicólogo e psiquiatra, porque eu estava me sentindo bem sobrecarregada. (E3)

Ficava muito ansiosa no trabalho, comia muito e tive aumento de peso. (E1)

Os entrevistados relataram sentir dores físicas em decorrência das atividades desempenhadas em seu trabalho, como dor nas costas, dor nos punhos, sugestiva de tendinite. Essas dores são em decorrência do trabalhado na ESF e afetam a saúde do trabalhador de enfermagem, precisando ausentar-se para fazer o tratamento adequado, como depoimentos:

Sinto dor nas costas e dor nos punhos, acho que é tendinite. (E3)

Estou com dores nas mãos e no punho. Já tive que faltar e até mesmo entrar em licença. (T6)

\section{Sugestões da equipe de enfermagem para melhoria da saúde do trabalhador}

Nesta categoria ressaltam-se sugestões trazidas pelos profissionais de enfermagem que foram entrevistados, a saber: 1) local para descanso; 2) reconhecimento do trabalho e 3) grupos terapêuticos. Na perspectiva dos entrevistados, estas são ideias que poderiam melhorar as questões que afetam diretamente a saúde da equipe de enfermagem da ESF. Enfim, um ambiente de trabalho mais saudável para a equipe de saúde.

Os entrevistados sugerem reformas na estrutura física da unidade da ESF, alegando que uma reestruturação no posto melhoraria as condições de trabalho e, consequentemente, a saúde da equipe como um todo. Nesse cenário, surge a ideia da criação de um local apropriado para o descanso durante o intervalo da jornada de trabalho, propiciando conforto e bem-estar para o trabalhador, como o recorte a seguir

Sugiro ter um lugar apropriado para descansar, que pudesse descansar as pernas, as costas um pouco. Que a pessoa possa descansar o corpo. (E5)

O reconhecimento do trabalho realizado na ESF foi uma sugestão trazida pelos entrevistados, pois o mesmo motiva o profissional e o estimula na realização das suas atividades, melhorando as condições de trabalho e, consequentemente, a saúde do trabalhador de enfermagem:

Teve uma vez que eu e uma colega minha passamos mais de uma semana trabalhando sozinhas. A gente fez tudo que podia ser feito. Daí, tu fica pensando quando éque eu vou poder ouvir de alguém algum elogio. Então, a gente vai se desgastando e se desmotivando, entende? (A4)

Evidencia-se nas falas abaixo que os entrevistados sentem necessidade de um momento de interação e de trocas com os colegas, fazendo desse encontro um momento de prazer e de melhoria das condições da saúde do trabalhador A criação de um grupo terapêutico surge como uma proposta, visando diminuir o estresse verbalizado por alguns trabalhadores da ESF.

Eu acho que está todo mundo estressado, eu acho que a gente precisava de grupos terapêuticos para os trabalhadores. (T3)

Otrabalhador teria que ter mais espaços prá poder sentar, falar e se expor. Poder interagir com os outros colegas. (A4) 


\section{DISCUSSÃO}

\section{Questões que afetam a saúde da equipe de enfermagem}

A grande demanda de atividades que os profissionais de enfermagem executam no dia a dia de trabalho agrava-se ainda mais com a falta de profissionais e com o grande absenteísmo daqueles que trabalham. Assim, a ESF, como eixo reorganizador da atenção básica, trouxe à tona problemas relacionados aos recursos humanos, como, por exemplo, a inadequação de composição das equipes frente às demandas sociais e demográficas ${ }^{(8)}$. Essa falta de profissionais acaba prejudicando a saúde dos trabalhadores que atuam nessa unidade e, consequentemente, afetando a assistência prestada à população da localidade.

Os entrevistados percebem que o espaço físico é pequeno para atender às necessidades da equipe e também dos próprios usuários. A reforma no espaço da unidade facilitaria um atendimento humanizado aos usuários, além de possibilitar um ambiente adequado para o desempenho do trabalho. Somado a isso, existe ainda a falta de materiais para realização de atendimento à população, como falta de lençol, travesseiro e maca, além de água, que prejudica a assistência de enfermagem na sala de curativos e de vacinas. A equipe de enfermagem, ao perceber o dano causado à população da área de abrangência da ESF, demonstra indignação sobre suas condições de trabalho, e até mesmo sofrimento em perceber que a falta de algum insumo vai além da sua competência.

Historicamente, a maioria das unidades de saúde possui infraestrutura deficiente e funciona em prédios adaptados. Dessa maneira, a precariedade dos espaços físicos destinados à realização das atividades de saúde a serem oferecidas aos cidadãos também é histórica, pois ainda pressupõe-se que qualquer espaço é adequado, bastando apenas contratar os profissionais e colocá-los à disposição das comunidades. Tal concepção tem levado a oferta de serviços de saúde a ser realizada em qualquer ambiente ${ }^{(9-10)}$.

A enfermagem mostra a sua insatisfação em relação ao seu trabalho através da questão salarial, quando percebe que não obtém um retorno financeiro que considera satisfatório para o desempenho de suas funções. Dessa maneira, a ausência de incentivo financeiro faz com que alguns profissionais exerçam a dupla ou tripla jornada de trabalho, prejudicando a saúde do trabalhador ${ }^{(11)}$. Assim, novos processos de trabalhos requerem posturas diferentes dos trabalhadores, redefinindo sua relação com seu trabalho, tendo em vista que questões como o salário e a sobrecarga precisam ser discutidas, avaliadas e resolvidas ${ }^{(12)}$.

Roubos, xingamentos, agressões físicas e ameaças de morte foram apontados pela equipe de enfermagem como aspectos estressores que afetam a saúde de quem trabalha na referida unidade. $\mathrm{O}$ ambiente de trabalho é de extrema importância para a saúde do trabalhador, pois ambientes considerados inseguros fazem com que os profissionais estejam sempre em situação de alerta ${ }^{(13)}$.

Salienta-se que os profissionais da ESF, a partir do alto grau de exigências e responsabilidades que assumem, necessitam estar muito próximos da realidade dos indivíduos, o que expõe o trabalhador a riscos físicos e/ou psicossociais, tornando-os vulneráveis ao estresse e sofrimento físico ${ }^{(14)}$.

Um entrevistado mostrou preocupação durante a realização da VD, na qual tem que desenvolver uma abordagem intitulada 'sutil', considerada como diferenciada para alguns moradores da comunidade, tendo em vista o seu envolvimento com o tráfico. Essa preocupação demonstra o quanto a questão da segurança afeta a saúde da equipe de enfermagem, exprimindo receio ao atender algumas família entendidas como violentas na comunidade.

A organização de equipes de saúde da família mostra que, ao desenvolver alguma atividade junto à comunidade, onde a realidade do indivíduo fica muito próxima, os problemas são de diversas ordens, as limitações internas e externas são incontáveis, expondo o profissional a riscos que podem desencadear o estresse ocupacional ${ }^{(13)}$.

Os membros da equipe da ESF atuam diretamente em diversas realidades que, em grande parte, são permeadas pela miséria, violência, más condições de higiene e de moradia, inúmeras precariedades e impossibilidades. Esse cenário de trabalho influencia de alguma forma o profissional, ao mesmo tempo em que exige certa adaptação, além de conhecimento e competência para implantar o cuidado neste contexto ${ }^{(13)}$.

Evidenciou-se que o trabalhador que sofre de alguma questão de ordem emocional muitas vezes não tem amparo da instituição que trabalha, tendo que procurar um tratamento particular. Talvez isso ocorra por não haver um serviço especializado para o atendimento ao trabalhador, ou mesmo por se perceber os sintomas de tristeza, avolia, ansiedade como sintomas de alguma doença psiquiátrica. Dessa forma, acredita-se na necessidade de as instituições de saúde proverem ambientes 
de cuidado aos cuidadores. Afinal, a realização de ações que incentivem o cuidado do cuidador no ambiente de trabalho certamente promoverá o bem-estar do profissional e a melhoria da qualidade dos serviços prestados.

O trabalho ocupa, também, um lugar fundamental na dinâmica do investimento afetivo das pessoas. Condições favoráveis à livre utilização das habilidades dos trabalhadores e ao controle do trabalho pelos trabalhadores têm sido identificadas como importantes requisitos para que o trabalho possa proporcionar prazer, bem-estar e saúde, deixando de provocar doenças. Por outro lado, o trabalho desprovido de significação, sem suporte social, não reconhecido ou que se constitua em fonte de ameaça à integridade física e/ou psíquica pode desencadear sofrimento psíquico ${ }^{(14)}$.

As doenças físicas, como, por exemplo, as Lesões por Esforço Repetitivo e os transtornos mentais relacionados ao trabalho resultam, não de fatores isolados, mas de contextos de trabalho em interação com o corpo e aparato psíquico dos trabalhadores. As ações implicadas no ato de trabalhar podem atingir o corpo, produzindo disfunções e lesões biológicas, mas também reações psíquicas, além de desencadear processos psicopatológicos especificamente relacionados às condições do trabalho ${ }^{(1,5)}$.

O reconhecimento dos aspectos salientados nesta categoria pelos entrevistados constitui-se importante ferramenta para análise e planejamento de ambientes de trabalho mais saudáveis, tendo em vista que estes interferem na saúde do trabalhador da unidade da ESF estudada. O ambiente de trabalho, bem como as questões advindas dele - salarial e de segurança, apresentaram-se como fonte geradora de sobrecarga, adoecimento e mal-estar, expressos nas vocalizações de queixas.

\section{Sugestões da equipe de enfermagem para melhoria da saúde do trabalhador}

Os fatores relacionados ao tempo e ao ritmo de trabalho são muito importantes na determinação, tanto do sofrimento psíquico quanto da doença física relacionada ao trabalho. Jornadas de trabalho longas, com poucas pausas destinadas ao descanso e/ou refeições de curta duração, em lugares desconfortáveis, de trabalho noturnos, alternados ou iniciando muito cedo, ritmos intensos ou monótonos, pressão de supervisores ou chefias por mais velocidade e produtividade causam, com frequência, quadros ansiosos, fadiga crônica e distúrbios do sono, entre outros ${ }^{(3)}$.

O cuidador enfrenta diversas situações e fatores no ambiente de trabalho que afetam a sua integridade física, psíquica e emocional. São causadores de estresse os altos níveis de poluição sonora, visual e do ar ambiente, a falta de lazer, o espaço físico inadequado e a instabilidade no emprego ${ }^{(1)}$.

Entende-se que o reconhecimento pelo trabalho executado é de extrema importância para o membro da equipe de enfermagem, uma vez que incentiva o profissional e o estimula na busca de um cuidado humanizado. Dessa forma, um entrevistado sugere como possibilidade de melhoria das condições de trabalho a necessidade de a chefia elogiar os trabalhadores da ESF, uma vez que este motiva o profissional para a execução de suas atividades, elevando sua autoestima ${ }^{(15)}$.

Nesse cenário, o grupo terapêutico tem por objetivo ampliar a vivência individual, acrescentando à experiência de cada participante também uma relação de grupo. Esses grupos possibilitam autoconhecimento, melhoram a autoimagem e a capacidade de relacionamento interpessoal, além do aumento da capacidade de percepção do ambiente ao qual pertence ${ }^{(16)}$. Dessa maneira, as instituições de saúde e os gerentes de serviços precisam abrir espaços para que os trabalhadores exercitem a prática do autocuidado e as relações interpessoais no âmbito da equipe ${ }^{(17-18)}$.

Nesta categoria, evidencia-se que a criação de um local para descanso, de grupos terapêuticos e o reconhecimento pelo trabalho executado são estratégias simples e que podem trazer repercussões positivas para a saúde do trabalhador na perspectiva dos entrevistados.

\section{CONSIDERAÇÕES FINAIS}

Este estudo objetivou a percepção dos trabalhadores de enfermagem sobre a saúde do trabalhador de enfermagem de uma unidade da ESF do Sul do país. A detecção dos fatores que afetam a saúde da equipe de enfermagem na ESF, apresentados na primeira categoria, ilustrou que as condições de trabalho influenciam diretamente a saúde do trabalhador. Fatores como a sobrecarga de trabalho, estrutura física precária e falta de incentivo financeiro levaram ao sofrimento físico e mental dos trabalhadores entrevistados.

Somado a essas questões, salienta-se que realidade dos entrevistados os expõe a uma série de situações de violência e agressões físicas e verbais, estando até mesmo sob o risco de vida.

A segunda categoria possibilitou conhecer as sugestões da equipe de enfermagem sobre idéias de melhoria da saúde do trabalhador, ao ouví-lo em suas 
necessidades. Essas sugestões permearam a ideia da construção de um espaço para descanso e um espaço de fala, além do desejo de ser reconhecido pelas atividades desempenhadas. Assim, faz-se necessário que os serviços promovam espaços de interação e de discussão sobre as questões do cotidiano, como estratégia de enfrentamento das inúmeras questões que afetam a saúde do trabalhador.

Os achados deste estudo podem contribuir para a formulação de estratégias de prevenção dos agravos à saúde que acometem os trabalhadores de enfermagem nas ESFs, bem como colaborar para melhoria dos serviços prestados. Portanto, enfatiza-se a necessidade de realizar mais estudos de cunho qualitativo, para dar voz aos trabalhadores das unidades da ESF. A saúde do trabalhador da equipe de enfermagem deve ser pauta de discussões com os gestores, visando melhorias das condições de trabalho que afetam diretamente a saúde desses profissionais e, consequentemente, a qualidade do atendimento prestado à população.

\section{REFERÊNCIAS}

1. Silva LA, Secco IAO, Dalri RCMB, Araújo AS, Romano CC, Silveira SE. Enfermagem do trabalho e ergonomia: prevenção de agravos à saúde. Rev. enferm. UERJ [Internet] 2011;19(2) [acesso em 13 jan 2012]. Disponível: http://www.facenf.uerj.br/v19n2/ v19n2a24.pdf

2. Shimizu HE, Ribeiro EJG. Acidentes de trabalho com trabalhadores de enfermagem. Rev Bras Enferm. 2007;60(5) [acesso em 13 jan 2012]. Disponível: http:// doi.org/10.1590/S0034-71672007000500010

3. Ministério da Saúde (BR). Política Nacional de Segurança e Saúde do Trabalhador [Internet]. Brasília; 2004 [acesso em 01 nov 2011]. Disponível: http://portal. saude.gov.br/portal/arquivos/pdf/insumos_portaria_ interministerial_800.pdf

4. Oliniski SR, Lacerda MR. Cuidando do cuidador no ambiente de trabalho: uma proposta de ação. Rev Bras Enferm. [Internet] 2006;59(1) [acesso em 15 jan 2012]. Disponível: http://dx.doi.org/10.1590/S003471672006000100019

5. Prestes FC, Beck CLC, Silva RM, Tavares JP, Camponogara S, Burg G. Prazer-sofrimento dos trabalhadores de enfermagem de um serviço de hemodiálise. Rev. Gaúcha Enferm. [Internet] 2010;31(4) [acesso em 05 fev 2012]. Disponível: http://dx.doi. org/10.1590/S1983-14472010000400018
6. Minayo MCS. O desafio do conhecimento: pesquisa qualitativa em saúde. 10ª ed. São Paulo: Hucitec; 2007.

7. Ministério da Saúde (BR), Conselho Nacional de Saúde. Resolução n. 196, de 10 de outubro de 1996: diretrizes e normas regulamentadoras de pesquisas envolvendo seres humanos. Brasília; 1996.

8. Conill EM. Ensaio histórico-conceitual sobre a atenção primária à saúde: desafios para a organização de serviços básicos e da Estratégia Saúde da Família em centros urbanos no Brasil. Cad. Saúde Pública [Internet] 2008;24 (supl.1) [acesso em 08 fev 2012] Disponível: http://dx.doi.org/10.1590/S0102-311X2008001300002.

9. Secretaria de Estado de Saúde (MG). Construindo ou reformando as Unidades Básicas de Saúde [Internet]. Belo Horizonte; 2004 [acesso em 15 set 2011]. Disponível: http://www.saude.mg.gov.br/ publicacoes/linha-guia/manuais/atencao-basica/ construindooureformandoasunidades18032005.pdf

10. Linard AG, Castro MM, Cruz AKL. Integralidade da assistência na compreensão dos profissionais da Estratégia Saúde da Família. Rev. Gaúcha Enferm. [Internet] 2011;32(3) [acesso em 20 mar 2012]. Disponível: http://dx.doi.org/10.1590/S198314472011000300016

11. Silva TL, Dias EC, Ribeiro ECO. Saberes e práticas do agente comunitário de saúde na atenção à saúde do trabalhador. Interface-Comunic., Saude, Educ. [Internet] 2011;15(38) [acesso em 17 fev 2012] . Disponível: http:// dx.doi.org/10.1590/S1414-32832011005000035

12. Marques D, Silva EM. A enfermagem e o Programa Saúde da Família: uma parceria de sucesso? Rev Bras Enferm. [Internet] 2004;57(5) [acesso em 11 abr 2012]. Disponível: http://dx.doi.org/10.1590/S003471672004000500006 .

13. Velloso ISC, Araújo MT, Alves M. Trabalhadores de uma Unidade Básica de Saúde na interface com a violência. Acta Paul. Enferm. [Internet] 2011;24(4) [acesso em 19 abr 2012]. Disponível: http://dx.doi. org/10.1590/S0103-21002011000400004.

14. Camelo SHH, Angerami ELS. Estratégias de gerenciamento de riscos psicossociais no trabalho das equipes de saúde da família. Rev. Eletr. Enf. [Internet] 2008;10(4) [acesso em 20 abr 2012]. Disponível: http:// www.fen.ufg.br/fen_revista/v10/n4/pdf/v10n4a04.pdf

15. Albornoz SG. As esferas do reconhecimento: uma introdução a Axel Honne,0th. Cad. psicol. soc. 
trab. [Internet] 2011;14(1) [acesso em 27 abr 2012]. Disponível: http://www.revistas.usp.br/cpst/article/ view/25720/27453

16. Grando MK, Dall'Agnol CM. Desafios do processo grupal em reuniões de equipe da estratégia saúde da família. Esc. Anna Nery [Internet] 2010;14(3) [acesso em 10 jan 2012]. Disponível: http://dx.doi.org/10.1590/ S1414-81452010000300011

17. Magalhães AMM, Riboldi CO, Dall'Agnol CM. Planejamento de recursos humanos de enfermagem: desafio para as lideranças. Rev Bras Enferm. [Internet] 2009;62(4) [acesso em 15 jan 2012]. Disponível: http:// dx.doi.org/10.1590/S1414-81452010000300011

18. Oliveira DT, Ferreira PJO, Mendonça LBA, Oliveira HS. Percepções do agente comunitário de saúde sobre sua atuação na estratégia saúde da família. Cogitare enferm. [Internet] 2012;17(1) [acesso em 20 fev 2012]. Disponível: http://ojs.c3sl.ufpr.br/ojs2/index.php/ cogitare/article/viewFile/26386/17580 